Send your letters to the Editor,

British Dental Journal,

64 Wimpole Street

London

W1G 8YS

Email bdj@bda.org

Priority will be given to letters less than 500 words long.

Authors must sign the letter, which

may be edited for reasons of space.

\section{HERBAL REMEDIES}

Sir, we wish to highlight an unusual case of post-operative bleeding following dental extraction that presented to the accident and emergency department at Manchester Royal Infirmary.

A 46-year-old Caucasian male presented complaining of continued bleeding from the operative site where he had undergone the extraction of an upper right first permanent molar earlier that day. The patient stated the extraction was uneventful and the tooth was removed as a whole by his GDP. Applying pressure to the area had not stopped the bleeding.

The patient's medical history was unremarkable. He was taking paracetamol $1 \mathrm{~g}$ and ibuprofen $400 \mathrm{mg}$ for pain relief as prescribed by his GDP. However, on further questioning the patient revealed that, for a number of years, he had been taking a host of vitamins and herbal remedies including gingko biloba, ginseng, garlic and ginger.

On examination poor clot formation was noted about the surgical site with a gentle ooze of blood present.

The bleeding was arrested with local measures including, an oxidised cellulose dressing (Surgicel) and resorbable sutures over the socket (Vicryl 3.0).

Whilst there are a number of case studies reporting post-operative bleeding in patients taking herbal remedies such as gingko biloba; few relate to dental surgery. ${ }^{1-5}$

This case further highlights the potential for post-operative complications and drug interactions in patients taking herbal remedies. A thorough medical and drug history must be taken from all patients. Unfortunately many patients feel they do not need to inform health professionals that they take herbal remedies, as they do not perceive them to be medically relevant.

N. Patel

1. Bent S, Goldberg H, Padula A, Avins A L. Spontaneous bleeding associated with ginkgo biloba: a case report and systematic review of the literature. J Gen Intern Med 2005; 20: 657-661.

2. Destro M W, Speranzini M B, Cavalheiro Filho $C$ Destro T, Destro C. Bilateral haematoma after rhytidoplasty and blepharoplasty following chronic use of Ginkgo biloba. Br J Plast Surg 2005; 58: 100-101.

3. Meisel C, Johne A, Roots I. Fatal intracerebral mass bleeding associated with Ginkgo biloba and ibuprofen. Atherosclerosis 2003; 167: 367.

4. Little J W. Complementary and alternative medicine: impact on dentistry. Oral Surg Oral Med Oral Pathol Oral Radiol Endod 2004; 98: 137-145.

5. Fessenden J M, Wittenborn W, Clarke L. Gingko biloba: a case report of herbal medicine and bleeding postoperatively from a laparoscopic cholecystectomy. Am Surg 2001; 67: 33-35.

DOI: $10.1038 /$ sj.bdj.2010.726

\section{CONTACT CARIES}

Sir, it was interesting to read the article Resin composite contours (BDJ 2010; 208: 395-401), which described a minimally invasive technique to restore the contact area, since this technique departs from the accepted procedure of cavity preparation of breaking the contact. The bulk of enamel caries occurs at the contact of two enamel surfaces, either between two adjoining teeth or between the two walls of a fissure on an occlusal surface.

I have studied the relationship of contact area and the carious lesion in several ways, one of which was to take an impression of a tooth prior to its extraction and then after extraction the tooth was repositioned in the set impression to help define the contact area. ${ }^{1}$ The relationship of the contact area and carious lesion was then studied. Most of the lesions were found to be within the confines of the contact area.

Wheeler published photographs of teeth showing carious lesions on their surfaces and if you compare the pictures of the carious lesions on the approximal surfaces with the figures of diagrammatic representation of the contact area, you will find that the carious lesion usually occurs at the contact area. ${ }^{2}$

The size of the lesion in Figure 11 seems to be fairly large and there is plenty of unsupported enamel in Figure 25. I am not sure that the unsupported enamel after bonding to the composite restorative material can become strong enough to withstand masticatory forces. The use of etching agents under the circumstances of poor accessibility, low visibility and close proximity to the pulp chamber may not be good for the vital pulp. It is very important to understand the disease before you can plan to treat it.

L. K. Bandlish, London

1. Bandlish L K. Colour atlas of a new concept of enamel caries. London: Bandlish, 1987.

2. Wheeler R C. Dental anatomy, physiology and occlusion. London: WB Saunders, 1974.

DOI: 10.1038/sj.bdj.2010.727

\section{RESORPTION ISSUES}

Sir, we enjoyed reading the recent paper on management of inflammatory root resorption using MTA obturation (BDJ 2010; 208: 287-289). The paper demonstrated a well obturated immature root canal using MTA.

The case fails to discuss the issues of replacement resorption which will ultimately lead to the loss of the tooth. In the clinical case description the tooth was kept dry for three hours prior to replantation. Therefore the chance of the periodontal ligament and cemental healing are very remote. ${ }^{1}$ In a growing child we would expect progressive replacement resorption and probable infraocclusion over the time frame described in the paper. ${ }^{2}$ Unfortunately no clinical photographs 
were provided or any consideration given to this outcome in the paper.

Furthermore the case demonstrated inflammatory root resorption despite pulp extirpation at the appropriate time, ten days after the initial injury. It is an interesting point for discussion as to why inflammatory root resorption occurred as the potential source of such a process should have been eliminated by pulp extirpation.

Finally, has this patient suffered dental trauma before? The UR 1 is considerably more immature than UL1 and this is suggestive of an earlier injury.

\section{N. Bhujel, P. Day, Leeds}

1. Andreasen J 0 , Borum $\mathrm{M}$, Jacobsen $\mathrm{H} \mathrm{L}$, Andreasen F M. Replantation of 400 avulsed permanent incisors. IV. Factors related to periodontal ligament healing. Endod Dental Traumatol 1995; 11: 76-89.

2. Andersson L, Malmgen B. The problem of dentoal veolar ankylosis and susbsequent replacement resorption in the growing patient. Aust Endod $J$ 1999; 25: 57-61.

Dr Vivek Aggarwal and Dr Mamta Singla respond: The reported case presented with severe inflammatory root resorption. Though replacement resorption is an important issue after tooth reimplantation, it was not evident in the present case. If I am not mistaken (sorry for my ignorance), Drs Bhujel and Day are assuming that the tooth was intentionally kept dry for three hours. The patient went to a local dentist after avulsion and there was a gap of three hours in avulsion and reimplantation. After three months of initial therapy, the mobility increased and the dentist referred the case to us. On careful examination of radiograph 1, it is obvious that the tooth was undergoing severe root resorption. After the MTA obturation, the resorption was arrested and there was no evidence of replacement resorption. Therefore no infraocclusion was seen. This is also obvious in the follow-up radiographs, where one can see and compare the level of incisal edges of both the incisors.

The extent of inflammatory resorption does not solely depend upon the pulp extirpation. It also depends upon the 'dry time', appropriate splinting and timely follow-up of the case. Unfortunately, in the present case, the dry time was three hours and there was no history of splinting the tooth. Finally the query of 'UR1 more immature than UL1'. The patient and his parents did not gave any prior history of trauma (other than the trauma which led to avulsion of the tooth). As described earlier the patient had an avulsed UR1 after a fall down stairs. The tooth was reimplanted without any history of splinting. The tooth had undergone inflammatory root resorption, leading to thinning of the root canal walls. Also resorption at the apical 1/3rd is evident. It has been described in the paper that 'the walls of the canal were thin, fragile and simulated a blunderbuss canal'.

We hope that we have clarified Drs Bhujel and Day's doubts.

DOI: 10.1038/sj.bdj.2010.728

\section{POORLY LED SERVICE}

Sir, may I congratulate you and your team on Volume 208 issue 10, a most thoughtprovoking edition of the $B D J$, in particular the opinion article Caries control in health service practice by Page, Weld and Kidd (BDJ 2010; 208: 449-450).

I have the pleasure of working with Jim Page and John Weld. Little did I know that these highly respected teachers promulgating best current NHS practice would feel the need to, albeit politely, expose the errors of prevalent thoughts and practices and their manifestations in the existing NHS primary dental care contract.

As part of the portfolio I was obliged to submit to our local deanery recently, one was asked to demonstrate knowledge of the range and scope of NHS dental care. This was part of my submission:

'...between the years of 1969 to 1990 the majority of my work was under NHS contract. After that only a small part of my practice was under NHS contract, since I was only too aware of the Range \& Scope of that service. Never the less I sat on the Isle of Wight Professional Executive Committee of the PCT, until they dispensed with dental representation. Also up until a couple of years ago I sat on the Hampshire Ct Isle of Wight LDC. I resigned because I believed I could no longer help patients or colleagues in their aspirations to gain benefit from the NHS dental service.'

My understanding of the NHS dental service is that it is an over-managed, underfunded, ill conceived, poorly led, shadow of its former self.

How long before we, again, get it right?

R. Burrows, Isle of Wight DOI: 10.1038/sj.bdj.2010.729 